\title{
Relationship of syrinx size and tonsillar descent to spinal deformity in Chiari malformation Type I with associated syringomyelia
}

\author{
Clinical article
}

\author{
Jakub Godzik, B.A., ${ }^{1}$ Michael P. Kelly, M.D., ${ }^{1}$ Alireza Radmanesh, M.D., ${ }^{4}$ \\ David Kim, B.S., ${ }^{2}$ Terrence F. Holekamp, M.D., Ph.D., ${ }^{2}$ Matthew D. Smyth, M.D., ${ }^{2,3}$ \\ Lawrence G. Lenke, M.D., ${ }^{1}$ Joshua S. Shimony, M.D., Ph.D., ${ }^{4}$ Tae Sung Park, M.D., ${ }^{2,3}$ \\ Jeffrey Leonard, M.D., ${ }^{2,3}$ ANd David D. Limbrick, M.D., Ph.D. ${ }^{2,3}$
}

Departments of ${ }^{1}$ Orthopaedic Surgery and ${ }^{2}$ Neurological Surgery; ${ }^{4}$ Mallinckrodt Institute of Radiology, Washington University School of Medicine; and ${ }^{3}$ Department of Pediatric Neurosurgery, St. Louis Children's Hospital, St. Louis, Missouri

\begin{abstract}
Object. Chiari malformation Type I (CM-I) is a developmental abnormality often associated with a spinal syrinx. Patients with syringomyelia are known to have an increased risk of scoliosis, yet the influence of specific radiographically demonstrated features on the prevalence of scoliosis remains unclear. The primary objective of the present study was to investigate the relationship of maximum syrinx diameter and tonsillar descent to the presence of scoliosis in patients with CM-I-associated syringomyelia. A secondary objective was to explore the role of craniovertebral junction $(\mathrm{CVJ})$ characteristics as additional risk factors for scoliosis.

Methods. The authors conducted a retrospective review of pediatric patients evaluated for CM-I with syringomyelia at a single institution in the period from 2000 to 2012. Syrinx morphology and CVJ parameters were evaluated with MRI, whereas the presence of scoliosis was determined using standard radiographic criteria. Multiple logistic regression was used to analyze radiological features that were independently associated with scoliosis.

Results. Ninety-two patients with CM-I and syringomyelia were identified. The mean age was $10.5 \pm 5$ years. Thirty-five (38\%) of 92 patients had spine deformity; 23 (66\%) of these 35 patients were referred primarily for deformity, and $12(34 \%)$ were diagnosed with deformity during workup for other symptoms. Multiple regression analysis revealed maximum syrinx diameter $>6 \mathrm{~mm}$ (OR 12.1, 95\% CI 3.63-40.57, $\mathrm{p}<0.001)$ and moderate $(5-12 \mathrm{~mm})$ rather than severe $(>12 \mathrm{~mm}$ ) tonsillar herniation (OR 7.64,95\% CI 2.3-25.31, p =0.001) as significant predictors of spine deformity when controlling for age, sex, and syrinx location.

Conclusions. The current study further elucidates the association between CM-I and spinal deformity by defining specific radiographic characteristics associated with the presence of scoliosis. Specifically, patients presenting with larger maximum syrinx diameters $(>6 \mathrm{~mm})$ have an increased risk of scoliosis. (http://thejns.org/doi/abs/10.3171/2014.1.PEDS13105)
\end{abstract}

\section{KEY WORDS • Chiari malformation • syringomyelia • scoliosis}

$\mathrm{C}$ HIARI malformation Type I (CM-I) is a developmental abnormality of the craniovertebral junction (CVJ), often associated with spinal cord abnormalities such as syringomyelia and scoliosis..$^{10,33}$ The rate of scoliosis in pediatric patients with CM-I has been reported to be as high as $80 \%$ in those with concurrent syringomyelia. ${ }^{6,10,16,20,31}$ Some authors have speculated that the etiology of scoliosis in such patients is related to the effect of the expanding spinal cord syrinx on the function of medially located motor neurons; the resulting imbalance in the paraspinal musculature is thought to predispose the individual to spinal deformity. ${ }^{11,13,18}$ Others

Abbreviations used in this paper: $\mathrm{AP}=$ anteroposterior; $\mathrm{CM}-\mathrm{I}=$ Chiari malformation Type I; CVJ = craniovertebral junction; CXA = clivus canal angle. have questioned the validity of this model and suggested tonsillar compression of the cervicomedullary junction as an alternate etiology of scoliosis in patients with CM-I. ${ }^{4}$

Despite the uncertain etiology, scoliosis in the context of syringomyelia and CM-I is frequently treated with decompression of the CVJ to stabilize the spinal deformity. ${ }^{7,8,15}$ Prior studies have demonstrated the importance of early neurosurgical intervention in patients with scoliosis to avoid or delay curve progression. ${ }^{6,716}$ While this approach is widely practiced, no guidelines are in place to identify the patients at risk for concurrent spinal deformity. Although authors have examined radiological features of CM-I-related scoliosis, none have reported the differences in the radiological features of syringomyelia and the CVJ between patients with and those without scoliosis.

We hypothesized that a larger maximum syrinx size 


\section{Syrinx size and scoliosis in Chiari malformation Type I}

portends a greater risk of spinal deformity. In the current study, we investigated the relationship between maximum syrinx diameter and the presence of scoliosis in patients with CM-I and syringomyelia. A secondary aim was to explore the role of $\mathrm{CVJ}$ characteristics as additional risk factors for scoliosis.

\section{Methods}

\section{Patient Population}

After obtaining institutional review board approval from Washington University School of Medicine and St. Louis Shriner's Hospital, where patients were co-managed, we queried a pediatric neurosurgical database for patients evaluated for CM-I with syringomyelia in the period between 2000 and 2012. Criteria for inclusion in the search were an age of 18 years or younger, diagnosis of CM-I (tonsillar descent beyond the foramen magnum $\geq 5 \mathrm{~mm}$ ), and maximum anteroposterior (AP) diameter of syringomyelia $\geq 2 \mathrm{~mm}$. Exclusion criteria were previous decompression or spinal fusion; missing preoperative MRI or radiographic studies; idiopathic syringomyelia or syringomyelia related to tumor, infection, arachnoiditis, or previous trauma to the spinal cord; history of myelomeningocele, tethered cord, or other dysraphism; and connective tissue diseases or genetic syndromes. We reviewed demographic data, presenting symptoms, neurological deficits, and medical comorbidities, as well as pre- and postoperative radiological studies.

\section{Imaging Data}

Two different investigators, including a board-certified radiologist, assessed features of the posterior cranial fossa and the CVJ by using brain or cervical spine MRI. They measured: 1) tonsillar herniation, as defined by the distance between the tip of the cerebellar tonsil perpendicular to McRae's line (basion-opisthion line); 2) position of the obex relative to the foramen magnum (quantified by the perpendicular distance between the obex and a line drawn from the basion perpendicular to the central canal); ${ }^{35,36} 3$ ) CM 1.5, if present (defined as descent of the obex below the foramen magnum); ${ }^{34,36}$ 4) $\mathrm{pb}-\mathrm{C} 2$, perpendicular distance between the ventral dura to the line that joins the basion to the posterior portion of the axis body inferior endplate $;{ }^{9} 5$ ) odontoid inclination (angle between the dens and the posterior wall of the $\mathrm{C}-2$ vertebral body); ${ }^{37} 6$ ) clivus canal angle (CXA; determined by the angle between the Wackenheim's clivus line and the posterior wall of the C-2 vertebral body); ${ }^{28,31}$ 7) basilar invagination, if present; ${ }^{27}$ and 8) medullary kinking, if present. ${ }^{27}$

The location and morphology of the syrinx were evaluated using both T1- and T2-weighted MRI. Sagittal images of the spine and brain were used to determine the rostral and caudal extent of the syrinx, recorded as the number of vertebral segments traversed (as described by Ono et al. ${ }^{20}$ ). Axial images were used to determine maximal AP diameter of the syrinx (in $\mathrm{mm}$ ). Results of CSF flow studies were obtained when available.

The location and severity of spinal deformity were recorded using the standard Cobb technique with available imaging. ${ }^{31}$ Scoliosis was defined as a Cobb angle $>$ $10^{\circ} .{ }^{14}$ Patients without available imaging records were ex- cluded from analysis, despite prior description of clinically significant scoliosis $\left(>10^{\circ}\right)$ in the medical records.

\section{Statistical Analysis}

Univariate statistical analysis was performed to identify the unadjusted association of basic demographic and radiological covariates with the presence of spinal deformity. Proportions were analyzed using Fisher's exact test, and continuous data were analyzed using univariate logistic regression. Tonsillar herniation and CXA were categorized using a cutoff of 1 SD from the mean. Collinearity between radiological covariates was examined using Pearson's correlation coefficients. Those covariates satisfying the statistical entry criteria $(\mathrm{p}<0.2)$ on univariate analysis were included in the logistic regression model. Multiple logistic regression analysis was performed to assess independent risk factors for spinal deformity while adjusting for age and sex. The Hosmer-Lemeshow test was used to check goodness-of-fit of the model, and the predictive value of the multivariate model was expressed using the c-statistic. Statistical significance was established using a cutoff of $\mathrm{p}<0.05$. Data were analyzed using SPSS version 19.0 software (IBM).

\section{Results}

\section{Patient Characteristics}

Basic demographic data and chief complaints of the 92 patients (51 females and 41 males) with CM-I and syringomyelia are presented in Table 1 . The overall mean age at syrinx diagnosis was $10 \pm 5$ years.

\section{Radiological Features of Study Population}

Syringomyelia was present in all patients in the study, with a mean maximal AP syrinx diameter of $5.9 \pm$ $3.9 \mathrm{~mm}$ and syrinx length of $10 \pm 5$ vertebral levels. The syrinx crossed the cervicothoracic junction in $52(56 \%)$ of 92 patients, was isolated to the thoracic or lumbar spine in $12(13 \%)$, and spanned the length of the spinal cord in $6(6 \%)$. On preoperative T1-weighted MRI, the mean cerebellar tonsillar herniation was $14.4 \pm 7.2 \mathrm{~mm}$, mean obex descent was $10.2 \pm 5.0 \mathrm{~mm}$, mean pb-C2 was $3.9 \pm$ $1.8 \mathrm{~mm}$, mean odontoid inclination angle was $16^{\circ} \pm 8^{\circ}$, and mean CXA was $155^{\circ} \pm 11^{\circ}$. Basilar invagination was identified in 3 patients and medullary kinking in 18 (20\%) of 92. There was no correlation between tonsillar descent (Spearman's $=-0.152, \mathrm{p}=0.149$ ) or CXA (Spearman's $=$ $-0.159, \mathrm{p}=0.131$ ) and maximum syrinx diameter. Syrinx size between the 2 groups of tonsillar descent $(>12 \mathrm{~mm}$, $5-12 \mathrm{~mm}$ ) was comparable (5.7 vs $6.1, \mathrm{p}=0.818$ ).

Cerebrospinal fluid flow studies were performed in 33 patients $(36 \%) ; 7(21 \%)$ of these patients demonstrated normal flow, $12(36 \%)$ demonstrated posterior flow restriction only, and $14(42 \%)$ demonstrated both anterior and posterior flow restriction. Tonsillar pulsation was observed in 14 patients (42\%). Flow restriction was more often observed in patients with severe tonsillar herniation than in those with moderate herniation $(100 \%$ vs $50 \%, \mathrm{p}=0.001)$; however, no difference existed in flow restriction between those with and those without scoliosis ( $100 \%$ vs $76 \%, \mathrm{p}=0.55)$. Syrinx 
J. Godzik et al.

TABLE 1: Basic demographic and clinical characteristics of 92 patients with CM-I and syringomyelia*

\begin{tabular}{lccc}
\hline \multicolumn{1}{c}{ Parameter } & w/o Scoliosis $(\%)$ & w/ Scoliosis $(\%)$ & p Value \\
\hline no. of patients & 57 & 35 & 0.696 \\
mean age at syrinx diagnosis in yrs & $10 \pm 5.3$ & $9.6 \pm 3.8$ & 0.490 \\
no. of males & $27(47)$ & $14(40)$ & 0.498 \\
mean BMl & $18 \pm 6.5$ & $19.2 \pm 6.5$ & - \\
chief complaint & $0(0)$ & $23(66)$ & - \\
$\quad$ scoliosis & $33(58)$ & $17(48)$ & - \\
neurological symptoms & $38(67)$ & $9(26)$ & - \\
headache & $19(33)$ & $14(40)$ & \\
combination of symptoms & &
\end{tabular}

* Values represent the means \pm standard deviation unless indicated otherwise. BMI = body mass index; $-=$ not applicable.

size was unrelated to extent of flow restriction $(\mathrm{p}=0.26)$ and presence of tonsillar pulsation $(\mathrm{p}=0.572)$. These data were excluded from multivariate analysis because of the limited number of patients with available CSF flow studies.

\section{Radiographic Features of Scoliosis}

Formal preoperative spine radiographs (standing AP and lateral long cassette radiographs) were available in 35 $(100 \%)$ of 35 patients. Thirty-five $(38 \%)$ of 92 patients had spine deformity; 14 were male and 21 were female $(\mathrm{p}=$ 0.472 ). Spinal deformity had been previously diagnosed in $23(66 \%)$ of the 35 and was diagnosed during workup for presenting symptoms in 12 (34\%). Preoperative radiographic records were available for review in all patients with scoliosis (Table 2). The mean major coronal Cobb angle was $30.4^{\circ} \pm 15^{\circ} ; 18$ curves $(51 \%)$ were apex left. The mean thoracic kyphosis was $47^{\circ} \pm 15^{\circ}$, with $32(91 \%)$ of 35 patients demonstrating a sagittal curve $>30^{\circ}$. Patients diagnosed with scoliosis prior to referral to our institution demonstrated a larger Cobb angle $\left(35^{\circ}\right.$ vs $\left.22^{\circ}, \mathrm{p}=0.017\right)$.

Of the 35 patients with spinal deformity, 15 (43\%) ultimately required definitive spinal fusion within 24 months of posterior fossa decompression. Surgeries were offered in cases in which the coronal deformity had progressed to more than $50^{\circ}$, as measured using the traditional Cobb technique. Before reaching this radiographic measure, all patients were nonoperatively treated with various techniques, according to physician and patient preferences. Patients requiring spinal reconstruction demonstrated greater initial coronal deformity $\left(40^{\circ}\right.$ vs $\left.25^{\circ}, \mathrm{p}=0.003\right)$ and greater sagittal deformity $\left(55^{\circ}\right.$ vs $\left.42^{\circ}, \mathrm{p}=0.027\right)$. An initial coronal Cobb angle $>30^{\circ}(\mathrm{p}=0.014)$ and kyphosis $>45^{\circ}(p=0.03)$ corresponded to a higher likelihood of scoliosis surgery. Age at decompression $(\mathrm{p}=0.786)$, sex $(p=0.176)$, body mass index $(p=0.779)$, preoperative maximal syrinx diameter $(\mathrm{p}=0.152)$, and tonsillar herniation $(\mathrm{p}=0.426)$ were not associated with scoliosis surgery.

\section{Radiological Features of Scoliosis}

Univariate analysis of radiological risk factors associated with scoliosis are presented in Table 3 . The presence of scoliosis was significantly associated with a larger maximum AP syrinx diameter (OR 1.5, 95\% CI 1.3-1.8, $\mathrm{p}<0.001$ ); a syrinx diameter $>6 \mathrm{~mm}$ corresponded to a higher rate of scoliosis (OR 6.80, 95\% CI 2.64-17.52, p < $0.001)$. The relationship between syrinx size and scoliosis is demonstrated in Fig. 1. A cervicothoracic syrinx was more common in patients with spinal deformity ( $83 \%$ vs $40 \%, \mathrm{p}=0.002)$. The mean tonsillar herniation was $11.7 \pm$ $5.7 \mathrm{~mm}$ in patients with scoliosis, as compared with 16.2 $\pm 7.6 \mathrm{~mm}$ in those without scoliosis (OR $0.898,95 \%$ CI $0.83-0.97, \mathrm{p}=0.004)$. Patients with tonsillar herniation of 5-12 mm were more likely to demonstrate scoliosis (OR $3.38,95 \%$ CI $1.40-8.16, p=0.007)$, despite no difference in syrinx size $(\mathrm{p}=0.818)$. No difference existed in the CXA $(\mathrm{p}=0.912), \mathrm{pb}-\mathrm{C} 2(\mathrm{p}=0.598)$, odontoid inclination $(\mathrm{p}=0.547)$, or presence of CM $1.5(\mathrm{p}=0.92)$ between patients with and without scoliosis.

Following multivariate logistic regression analysis, maximum syrinx diameter $>6 \mathrm{~mm}$ (OR 12.1, 95\% CI

TABLE 2: Radiographic features of scoliosis in 35 patients with CM-I and syringomyelia*

\begin{tabular}{ll}
\hline \multicolumn{1}{c}{ Parameter } & Value \\
\hline mean age in yrs & $10 \pm 4$ \\
no. of males (\%) & $14(40)$ \\
mean BMI & $21 \pm 8$ \\
coronal & \\
mean major Cobb angle & $30.4 \pm 15^{\circ}$ \\
no. of convex It curves (\%) & $18(51)$ \\
apex: IQR & T8-11 \\
mean proximal thoracic Cobb angle & $14 \pm 11^{\circ}$ \\
mean middle thoracic Cobb angle & $27 \pm 17^{\circ}$ \\
mean thoracolumbar Cobb angle & $17 \pm 11^{\circ}$ \\
mean coronal balance in mm & $10 \pm 9$ \\
sagittal & \\
mean major Cobb angle $\dagger$ & $47 \pm 15^{\circ}$ \\
mean T2-5 Cobb angle & $15 \pm 7^{\circ}$ \\
mean T5-12 Cobb angle & $31 \pm 19^{\circ}$ \\
mean T12-S1 Cobb angle & $55 \pm 17^{\circ}$ \\
apex: IQR & $\mathrm{T} 6-8$ \\
\hline
\end{tabular}

* $\mathrm{QQR}=$ interquartile range.

$\dagger$ Ninety-one percent of patients had sagittal Cobb angle $>30^{\circ}$. 
Syrinx size and scoliosis in Chiari malformation Type I

TABLE 3: Univariate analysis of radiological features associated with scoliosis in patients with CM-I and syringomyelia

\begin{tabular}{|c|c|c|c|c|}
\hline Parameter & w/o Scoliosis (\%) & w/ Scoliosis (\%) & $\begin{array}{l}\text { p Value } \\
\text { (2-sided) }\end{array}$ & OR $(95 \% \mathrm{Cl})$ \\
\hline no. of patients & 57 & 35 & & \\
\hline \multicolumn{5}{|l|}{ CVJ } \\
\hline mean tonsillar herniation in mm & $16.2 \pm 7.6$ & $11.7 \pm 5.7$ & 0.004 & $0.898(0.832-0.969)$ \\
\hline no. w/ tonsillar herniation of $5-12 \mathrm{~mm}$ & $19(33)$ & $22(63)$ & 0.007 & $3.385(1.405-8.155)$ \\
\hline no. w/ CM 1.5 & $17(30)$ & $11(31)$ & 0.920 & $1.07(0.433-2.68)$ \\
\hline mean obex descent in $\mathrm{mm}$ & $11 \pm 5$ & $9.1 \pm 4.7$ & 0.084 & $1.084(0.989-1.187)$ \\
\hline no. $w /$ obex $<11 \mathrm{~mm}$ & $28(49)$ & $12(34)$ & 0.144 & $0.552(0.218-1.249)$ \\
\hline mean odontoid pb-C2 in mm & $3.8 \pm 1.9$ & $4 \pm 1.6$ & 0.598 & $1.067(0.842-1.351)$ \\
\hline mean dens inclination & $15.9 \pm 7.8^{\circ}$ & $14.9 \pm 7.7^{\circ}$ & 0.547 & $0.983(0.930-1.039)$ \\
\hline mean CXA & $155.5 \pm 10.8^{\circ}$ & $155.8 \pm 11.4^{\circ}$ & 0.912 & $1.002(0.964-1.042)$ \\
\hline no. $w / C X A>150^{\circ}$ & $37(65)$ & $22(63)$ & 0.755 & $1.151(0.447-2.777)$ \\
\hline no. w/ basilar invagination & $2(4)$ & $1(3)$ & 0.865 & $1.236(0.108-14.16)$ \\
\hline no. w/ medullary kinking & $13(23)$ & $5(14)$ & 0.321 & $1.773(0.572-5.493)$ \\
\hline \multicolumn{5}{|l|}{ syrinx morphology } \\
\hline mean syrinx diameter in mm & $4.1 \pm 3$ & $8.9 \pm 3.4$ & $<0.001$ & $1.537(1.285-1.839)$ \\
\hline no. w/ syrinx diameter $>6 \mathrm{~mm}$ & $17(30)$ & $26(74)$ & $<0.001$ & $6.797(2.637-17.521)$ \\
\hline no. w/ syrinx diameter $>7 \mathrm{~mm}$ & $10(18)$ & $24(68)$ & $<0.001$ & $10.255(3.82-27.53)$ \\
\hline mean syrinx length (no. of levels) & $8.1 \pm 5$ & $13.8 \pm 4$ & $<0.001$ & $1.264(1.136-1.406)$ \\
\hline \multicolumn{5}{|l|}{ syrinx location } \\
\hline no. cervical & $21(37)$ & $1(3)$ & - & - \\
\hline no. cervicothoracic & $23(40)$ & $29(83)$ & 0.002 & $26.5(3.31-211.8)$ \\
\hline no. thoracolumbar & $9(16)$ & $3(9)$ & 0.111 & $7(0.639-76.708)$ \\
\hline no. holocord & $4(7)$ & $2(6)$ & 0.079 & $10.5(0.758-145.35)$ \\
\hline \multicolumn{5}{|l|}{ CSF flow studies } \\
\hline no. w/ flow study performed & $29(51)$ & $4(11)$ & $<0.001$ & - \\
\hline no. w/ flow restriction & $22(76)$ & $4(100)$ & 0.555 & - \\
\hline no. w/ tonsillar pulsation & $11(38)$ & $3(75)$ & 0.279 & - \\
\hline
\end{tabular}

3.63-40.57, $\mathrm{p}<0.001)$ and moderate tonsillar herniation $(5-12 \mathrm{~mm}$; OR 7.64, 95\% CI 2.3-25.31, p = 0.001) remained independently associated with the presence of spine deformity when adjusted for age, sex, and syrinx location (Table 4). No significant interactions were found. The model was stable and robust with a Hosmer-Lemeshow chi-square of $0.28(\mathrm{p}=0.869)$ and c-statistic of 0.807 ( $\mathrm{p}<0.001)$.

\section{Discussion}

We have shown a strong association of the radiological features of syringomyelia and the CVJ with scoliosis in 92 children with CM-I and syringomyelia. Specifically, a larger maximum syrinx diameter and moderate $(5-12 \mathrm{~mm})$ rather than severe $(>12 \mathrm{~mm})$ tonsillar ectopia were independently associated with a higher frequency of scoliosis. No association was observed between syrinx location and the presence of scoliosis when adjusted for syrinx size. While the severity of the spinal deformity did not correlate with the diameter of the syrinx, patients with more severe initial deformity (scoliosis $>30^{\circ}$ or kyphosis $>45^{\circ}$ ) were more likely to require surgery for deformity correction despite decompression.
Previous authors have recognized the association among CM-I, scoliosis, and syringomyelia.6,20,36 The atypical patterns of CM-I-related deformities, such as left thoracic apices and hyperkyphosis, rapid progression, and early onset, suggest an etiology unique from that of adolescent idiopathic scoliosis. ${ }^{24,38}$ Both syringomyelia and hindbrain compression have been hypothesized in the pathogenesis of CM-I-related scoliosis; however, the role of each as a risk factor remains poorly defined. . $^{3,21,25,26}$ Although previous studies have recognized that CM-I patients with syringomyelia are more likely to demonstrate scoliosis,,${ }^{16,20,36}$ risk factors for clinically significant spinal deformity and the need for corrective spinal surgery are still debated. . $^{2021,24}$

Both Ozerdemoglu et al. ${ }^{21}$ and Qiu et al. ${ }^{24}$ have explored the relationship between syrinx morphology and spinal deformity characteristics. In a series of 112 pediatric patients with scoliosis, Ozerdemoglu and colleagues reported a range of syrinx diameters $(2-18 \mathrm{~mm})$ with no correlation to curve magnitude. ${ }^{21}$ Recently, Qiu et al. ${ }^{24}$ found no association between syrinx length or ratio of syrinx/cord diameter and curve severity in 83 patients. Similar to the study by Yeom et al., ${ }^{39}$ the current study revealed no association between syrinx characteristics and 


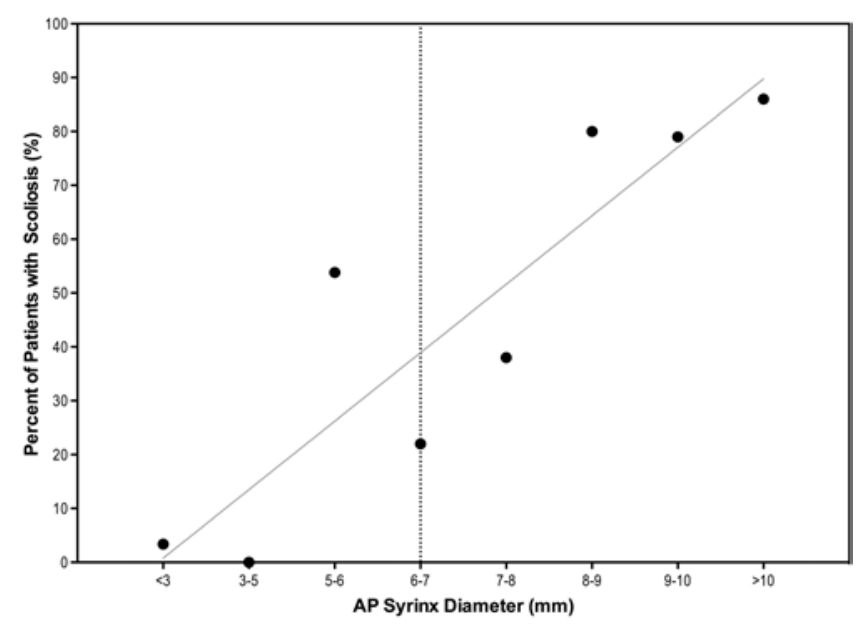

FIG. 1. A scatterplot of scoliosis frequency against maximal AP syrinx diameter. Patients with a larger maximal syrinx diameter have scoliosis at a higher frequency. A maximum AP syrinx diameter $>6 \mathrm{~mm}$ indicates a higher prevalence of scoliosis.

coronal Cobb angle. Only Ono et al..$^{20}$ noted a correlation between scoliosis severity $\left(12.1^{\circ}\right.$ vs $\left.37.7^{\circ}\right)$ and syrinx length (13.4 vs 15.9 levels) in an adult population with CM-I. Yet, in a study by Krieger et al., ${ }^{16}$ all 79 patients with CM-I and scoliosis demonstrated a syrinx width > $6 \mathrm{~mm}$. Recognizing the strong association between syrinx parameters and scoliosis, these authors implicated syrinx size in spinal growth. The preliminary association between greater maximum syrinx diameter and scoliosis in the current study builds on and significantly strengthens this theory. As we have shown, patients with a syrinx diameter $>6 \mathrm{~mm}$ demonstrate a significantly higher rate of scoliosis (OR 12.1). This finding also suggests that the mechanisms involved in scoliosis development may be distinct from those involved in curve progression, as syrinx size does not appear to be associated with the magnitude of coronal deformity.

Some authors describe a spatial component in the relationship between syringomyelia and scoliosis in CM-I. ${ }^{21}$ Ozerdemoglu et al. ${ }^{21}$ found that patients with a caudally located maximal syrinx diameter demonstrated distal major curve apices. The cervicothoracic junction was most often affected by a syrinx, with the largest syrinx area in the C5-7 region. Attenello et al. ${ }^{1}$ found that the majority of patients with scoliosis demonstrated cervical $(90 \%)$ and thoracic (95\%) syringes. Tokunaga et al. ${ }^{32}$ described a syrinx at the cervicothoracic junction in $96 \%$ (22 of 23) of patients with scoliosis. The mean syrinx/spinal cord ratio in their study was $49 \%$, with maximum dilation occurring most often at the C-6 level (17 of 23 cases). The current study showed a higher rate of scoliosis among cervicothoracic and holocord syringes on univariate analysis; however, when ad- justed for syrinx length and maximum diameter, syrinx location did not confer an additional risk for scoliosis. This may suggest the susceptibility of the cervicothoracic junction to syrinx expansion and highlights the strength of the association between syrinx size and scoliosis. ${ }^{21}$

The prevalence of scoliosis in CM-I without syringomyelia has been reported in $8 \%-30 \%$ of patients. ${ }^{19,31}$ Some authors suggest that this prevalence implicates tonsillar herniation as the underlying etiology of CM-I-related scoliosis, while others argue that this rate may reflect a basal level of scoliosis unrelated to CM-I. ${ }^{16}$ Although this unique patient population was not included in the current study design, we intend to investigate it in a future study.

Few studies have shown a direct association between CVJ parameters and scoliosis in CM-I patients with or without syringomyelia. Only Ono et al. ${ }^{20}$ reported a relation between levels of tonsillar descent and spinal deformity characteristics; they documented $70 \%$ concordance between the laterality of cerebellar tonsil asymmetry and the direction of major curve convexity. To our knowledge, no previous study has found moderate tonsillar ectopia $(5-12 \mathrm{~mm})$ to be associated with scoliosis in patients with CM-I and syringomyelia. Attenello et al. ${ }^{1}$ found that $90 \%$ of patients with CM-I and scoliosis demonstrated "moderate ectopia," which was defined as tonsillar descent between C-1 and C-2. Similar to the value noted in the current study, Tokunaga et al..$^{32}$ reported a mean tonsillar herniation of $9.7 \mathrm{~mm}$ in 23 patients with CM-I-related scoliosis. Other studies have also found a high proportion of patients with moderate descent. Qiu et al. ${ }^{24}$ showed that $44 \%$ of tonsils descended to the region between the foramen magnum and the C-1 level in 87 patients with scoliosis. They found no correlation between tonsillar herniation and curve severity. In a study of CM-I-related scoliosis, Krieger et al. ${ }^{16}$ found that $84 \%$ of patients had tonsils above the C-2 level.

It is surprising that patients with only moderate tonsillar ectopia $(5-12 \mathrm{~mm})$ have a greater risk of clinically significant scoliosis, whereas patients with more severe tonsillar descent $(>12 \mathrm{~mm}$ ) demonstrate a lower prevalence of scoliosis. While no difference in syrinx size exists between the 2 groups, several studies have reported a similarly perplexing association between moderate ectopia and the presence of syringomyelia in CM-I. ${ }^{23,30,37}$ In light of this observation, our findings may reflect a complex process at the CVJ. ${ }^{17}$ Several authors have suggested that the degree of obex descent at the CVJ could influence the spinal axis and the development of syringomyelia. ${ }^{29}$ Yet, we observed no association between obex descent and the presence of CM 1.5 with scoliosis. Although dynamic imaging of CSF flow in patients with CM has helped shape our understanding of the pathophysiology of syringomyelia, ${ }^{5}$ we were unable to include these studies in the multivariate analysis

TABLE 4: Independent risk factors for scoliosis in patients with CM-I and syringomyelia*

\begin{tabular}{cccr}
\hline Parameter & OR & $95 \% \mathrm{Cl}$ & $\mathrm{p}$ Value \\
\hline max syrinx diameter $>6 \mathrm{~mm}$ & 12.1 & $3.63-40.57$ & $<0.001$ \\
tonsillar herniation of $5-12 \mathrm{~mm}$ & 7.64 & $2.3-25.31$ & 0.001 \\
\hline
\end{tabular}

* Hosmer-Lemeshow chi-square $=0.28, p=0.869$. 


\section{Syrinx size and scoliosis in Chiari malformation Type I}

because of the small number of patients with complete testing. Likely, there is a dynamic component to the development of scoliosis that warrants further investigation using dynamic imaging.

Ultimately, the goal of decompression in CM-I patients with scoliosis is to stabilize curve progression and thereby prevent the need for complex spinal reconstruction. Although the natural history of scoliosis in CM-I remains unclear, a recent meta-analysis by Hwang et al. ${ }^{12}$ suggests the benefit of decompression and syrinx reduction in improving scoliotic curve progression. But despite adequate posterior fossa decompression, the rate of scoliosis surgery ranges between $15 \%$ and $50 \%$, comparable with the $43 \%$ described in the current study., ${ }^{2,6,16,25}$ Past authors have described an older age, level of spinal deformity, extent of syrinx resolution, and degree of initial scoliosis as risk factors for curve progression and spinal fusion. ${ }^{1,2,6,12,22,25}$ In the largest study to date, Krieger et al. ${ }^{16}$ noted a higher rate of surgery in patients with an initial Cobb angle $>25^{\circ}$, with no association with preoperative syrinx size or extent of syrinx resolution. Similarly, we observed that patients with scoliosis $>30^{\circ}$ as well as those with kyphosis $>50^{\circ}$ were significantly more likely to require spinal reconstruction within the follow-up period. However, the decision to perform spinal reconstruction involves multiple variables, among which are patient and physician preferences. While it is likely that early intervention plays a role in avoiding surgery, additional studies are needed to adequately determine the optimal management of spinal health in these complex cases.

A central limitation of our study is its retrospective, cross-sectional design. The data and their interpretation are limited by completeness of the medical records and consistency between preoperative evaluations, particularly the availability of standing plain films of the spine. A number of patients did not seek orthopedic care at our institution, thus limiting our ability to capture longitudinal data and examine the temporal relationship among syringomyelia, scoliosis development, and scoliosis surgery. Importantly, our study population included only those patients with syringomyelia $\geq 2 \mathrm{~mm}$ on MRI evaluation; we hope to investigate patients with CM-I-related scoliosis without syringomyelia in the future. Note also that this study is subject to the bias of a tertiary care referral center, as the composition of our study population represents only those patients referred to our clinic. To capture the true incidence of spinal deformity in patients with CM-I and better understand risk factors of progression and functional outcome, future research in this field must come in the form of a prospective, multicenter effort such as that of the Park-Reeves Syringomyelia Research Consortium.

No study has examined radiological features of the $\mathrm{CVJ}$ and syringomyelia as potential risk factors for the presence of scoliosis in CM-I with syringomyelia. We have shown that coexistent scoliosis is more likely with a larger maximum syrinx diameter and moderate tonsillar herniation $(5-12 \mathrm{~mm})$. While the results of this study have limited clinical implications, the findings presented herein suggest that dilation of the spinal cord by syringomyelia, as well as compression at the cervicomedullary junction, appears to influence spinal growth in CM-I.
Prospective studies conducted through the Park-Reeves Syringomyelia Research Consortium are directed toward further elucidating these complex relationships.

\section{Conclusions}

Results from this retrospective study demonstrate a strong association between maximum syrinx size and the presence of spinal deformity in patients with CM-I and syringomyelia. This finding represents an early but important component in the investigation of potential common mechanisms involved in the pathogenesis of these complex conditions.

\section{Acknowledgments}

We acknowledge the generosity of Sam and Betsy Reeves and their support of the Park-Reeves Syringomyelia Research Consortium. We also thank Mike Lehmkuhl for providing assistance with project oversight and Mike Wallendorf, Ph.D., Department of Biostatistics at Washington University in St. Louis, for assisting with univariate and multivariate statistical analysis.

\section{Disclosure}

This work was supported in part by the Park-Reeves Syringomyelia Research Consortium (Award No. UL1 TR000448) and the Clinical and Translational Science Award (No. TL1 TR000449) program of the National Center for Advancing Translational Sciences of the NIH. Dr. Limbrick has technology licensed to Allied Minds Inc. for an unrelated project. The spine service of Washington University, Department of Orthopaedic Surgery, receives grant monies from Axial Biotech and DePuy Spine. Dr. Lenke shares numerous patents with Medtronic (unpaid). He is a past president of the Scoliosis Research Society; on the associate editorial board of Spine; on the editorial board of the Journal of Spinal Disorders and Techniques and Scoliosis; on the professional advisory board of Backtalk and the Scoliosis Association; on the associate board of the Journal of Neurosurgery: Spine and The Spine Journal; an associate editor for iscoliosis.com and spineuniverse.com; and the deputy editor of Spine Deformity, all of which are unpaid positions. Dr. Lenke also receives or has received reimbursement from AMCICO, AOSpine, COA, BroadWater, DePuy, Dubai Spine Society, Medtronic, SOSORT, The Spinal Research Foundation, Scoliosis Research Society, and SSF for meetings and/or courses; royalties from Medtronic and Quality Medical Publishing, Washington University; grant monies from Axial Biotech, DePuy Synthes Spine, AOSpine, and Scoliosis Research Society; philanthropic research funding from the Fox Family Foundation; and fellowship funding from AOSpine North America.

Author contributions to the study and manuscript preparation include the following. Conception and design: Kelly, Kim, Lenke, Park, Limbrick. Acquisition of data: Godzik, Radmanesh, Kim, Holekamp, Smyth, Shimony. Analysis and interpretation of data: Godzik, Kelly. Drafting the article: Godzik, Kelly. Critically revising the article: all authors. Reviewed submitted version of manuscript: all authors. Approved the final version of the manuscript on behalf of all authors: Godzik. Administrative/technical/material support: Park. Study supervision: Limbrick.

\section{References}

1. Attenello FJ, McGirt MJ, Atiba A, Gathinji M, Datoo G, Weingart J, et al: Suboccipital decompression for Chiari malformation-associated scoliosis: risk factors and time course of deformity progression. J Neurosurg Pediatr 1:456-460, 2008

2. Bhangoo R, Sgouros S: Scoliosis in children with Chiari Irelated syringomyelia. Childs Nerv Syst 22:1154-1157, 2006 
3. Brockmeyer D, Gollogly S, Smith JT: Scoliosis associated with Chiari 1 malformations: the effect of suboccipital decompression on scoliosis curve progression: a preliminary study. Spine (Phila Pa 1976) 28:2505-2509, 2003

4. Brockmeyer DL: Editorial. Chiari malformation Type I and scoliosis: the complexity of curves. J Neurosurg Pediatr 7: 22-24, 2011

5. Ellenbogen RG, Armonda RA, Shaw DW, Winn HR: Toward a rational treatment of Chiari I malformation and syringomyelia. Neurosurg Focus 8(3):E6, 2000

6. Eule JM, Erickson MA, O'Brien MF, Handler M: Chiari I malformation associated with syringomyelia and scoliosis: a twenty-year review of surgical and nonsurgical treatment in a pediatric population. Spine (Phila Pa 1976) 27:1451-1455, 2002

7. Farley FA, Puryear A, Hall JM, Muraszko K: Curve progression in scoliosis associated with Chiari I malformation following suboccipital decompression. J Spinal Disord Tech 15: 410-414, 2002

8. Ghanem IB, Londono C, Delalande O, Dubousset JF: Chiari I malformation associated with syringomyelia and scoliosis. Spine (Phila Pa 1976)22:1313-1318, 1997

9. Grabb PA, Mapstone TB, Oakes WJ: Ventral brain stem compression in pediatric and young adult patients with Chiari I malformations. Neurosurgery 44:520-528, 1999

10. Hankinson TC, Klimo P Jr, Feldstein NA, Anderson RCE, Brockmeyer D: Chiari malformations, syringohydromyelia and scoliosis. Neurosurg Clin N Am 18:549-568, 2007

11. Huebert HT, MacKinnon WB: Syringomyelia and scoliosis. J Bone Joint Surg Br 51:338-343, 1969

12. Hwang SW, Samdani AF, Jea A, Raval A, Gaughan JP, Betz RR, et al: Outcomes of Chiari I-associated scoliosis after intervention: a meta-analysis of the pediatric literature. Childs Nerv Syst 28:1213-1219, 2012

13. Isu T, Iwasaki Y, Akino M, Abe H: Hydrosyringomyelia associated with a Chiari I malformation in children and adolescents. Neurosurgery 26:591-597, 1990

14. Kane WJ: Scoliosis prevalence: a call for a statement of terms. Clin Orthop Relat Res (126):43-46, 1977

15. Klekamp J: Surgical treatment of Chiari I malformationanalysis of intraoperative findings, complications, and outcome for 371 foramen magnum decompressions. Neurosurgery 71:365-380, 2012

16. Krieger MD, Falkinstein Y, Bowen IE, Tolo VT, McComb JG: Scoliosis and Chiari malformation Type I in children. Clinical article. J Neurosurg Pediatr 7:25-29, 2011

17. Meadows J, Kraut M, Guarnieri M, Haroun RI, Carson BS: Asymptomatic Chiari Type I malformations identified on magnetic resonance imaging. J Neurosurg 92:920-926, 2000

18. Mejia EA, Hennrikus WL, Schwend RM, Emans JB: A prospective evaluation of idiopathic left thoracic scoliosis with magnetic resonance imaging. J Pediatr Orthop 16:354-358, 1996

19. Milhorat TH, Chou MW, Trinidad EM, Kula RW, Mandell M, Wolpert C, et al: Chiari I malformation redefined: clinical and radiographic findings for 364 symptomatic patients. Neurosurgery 44:1005-1017, 1999

20. Ono A, Ueyama K, Okada A, Echigoya N, Yokoyama T, Harata S: Adult scoliosis in syringomyelia associated with Chiari I malformation. Spine (Phila Pa 1976) 27:E23-E28, 2002

21. Ozerdemoglu RA, Denis F, Transfeldt EE: Scoliosis associated with syringomyelia: clinical and radiologic correlation. Spine (Phila Pa 1976) 28:1410-1417, 2003

22. Ozerdemoglu RA, Transfeldt EE, Denis F: Value of treating primary causes of syrinx in scoliosis associated with syringomyelia. Spine (Phila Pa 1976) 28:806-814, 2003

23. Pillay PK, Awad IA, Little JR, Hahn JF: Symptomatic Chiari malformation in adults: a new classification based on mag- netic resonance imaging with clinical and prognostic significance. Neurosurgery 28:639-645, 1991

24. Qiu Y, Zhu Z, Wang B, Yu Y, Qian B, Zhu F: Radiological presentations in relation to curve severity in scoliosis associated with syringomyelia. J Pediatr Orthop 28:128-133, 2008

25. Sengupta DK, Dorgan J, Findlay GF: Can hindbrain decompression for syringomyelia lead to regression of scoliosis? Eur Spine J 9:198-201, 2000

26. Sgouros S, Kountouri M, Natarajan K: Posterior fossa volume in children with Chiari malformation Type I. J Neurosurg 105 (2 Suppl):101-106, 2006

27. Smoker WR: Craniovertebral junction: normal anatomy, craniometry, and congenital anomalies. Radiographics 14:255-277, 1994

28. Smoker WR, Khanna G: Imaging the craniocervical junction. Childs Nerv Syst 24:1123-1145, 2008

29. Stevens JM, Serva WA, Kendall BE, Valentine AR, Ponsford JR: Chiari malformation in adults: relation of morphological aspects to clinical features and operative outcome. J Neurol Neurosurg Psychiatry 56:1072-1077, 1993

30. Stovner LJ, Rinck P: Syringomyelia in Chiari malformation: relation to extent of cerebellar tissue herniation. Neurosurgery 31:913-917, 1992

31. Strahle J, Muraszko KM, Kapurch J, Bapuraj JR, Garton HJ, Maher CO: Chiari malformation Type I and syrinx in children undergoing magnetic resonance imaging. Clinical article. J Neurosurg Pediatr 8:205-213, 2011

32. Tokunaga M, Minami S, Isobe K, Moriya H, Kitahara H, Nakata Y: Natural history of scoliosis in children with syringomyelia. J Bone Joint Surg Br 83:371-376, 2001

33. Tubbs RS, Beckman J, Naftel RP, Chern JJ, Wellons JC III, Rozzelle CJ, et al: Institutional experience with 500 cases of surgically treated pediatric Chiari malformation Type I. Clinical article. J Neurosurg Pediatr 7:248-256, 2011

34. Tubbs RS, Elton S, Grabb P, Dockery SE, Bartolucci AA, Oakes WJ: Analysis of the posterior fossa in children with the Chiari 0 malformation. Neurosurgery 48:1050-1055, 2001

35. Tubbs RS, Iskandar BJ, Bartolucci AA, Oakes WJ: A critical analysis of the Chiari 1.5 malformation. J Neurosurg 101 (2 Suppl):179-183, 2004

36. Tubbs RS, McGirt MJ, Oakes WJ: Surgical experience in 130 pediatric patients with Chiari I malformations. J Neurosurg 99:291-296, 2003

37. Tubbs RS, Wellons JC III, Blount JP, Grabb PA, Oakes WJ: Inclination of the odontoid process in the pediatric Chiari I malformation. J Neurosurg 98 (1 Suppl):43-49, 2003

38. Wu L, Qiu Y, Wang B, Zhu ZZ, Ma WW: The left thoracic curve pattern: a strong predictor for neural axis abnormalities in patients with "idiopathic" scoliosis. Spine (Phila Pa 1976) 35:182-185, 2010

39. Yeom JS, Lee CK, Park KW, Lee JH, Lee DH, Wang KC, et al: Scoliosis associated with syringomyelia: analysis of MRI and curve progression. Eur Spine J 16:1629-1635, 2007

\footnotetext{
Manuscript submitted March 4, 2013.

Accepted January 6, 2014.

Portions of this work were presented in poster form at the Scoliosis Research Society 47th Annual Meeting held in Chicago, Illinois, on September 18, 2012, and the AANS/CNS Joint Section on Pediatric Neurosurgery held in St. Louis, Missouri, on November 28, 2012.

Please include this information when citing this paper: published online February 14, 2014; DOI: 10.3171/2014.1.PEDS13105.

Address correspondence to: Jakub Godzik, B.A., Department of Orthopaedic Surgery, Washington University School of Medicine, 660 S. Euclid Ave., Campus Box 8233, St. Louis, MO 63110. email: godzikj@wusm.wustl.edu.
} 